\title{
DEVELOPMENT OF NATURAL AND MODIFIED GUM BASED SUSTAINED-RELEASE FILM-COATED TABLETS CONTAINING POORLY WATER-SOLUBLE DRUG
}

\author{
AJAY KUMAR SHUKLA*, RAM SINGH BISHNOI, MANISH KUMAR, C.P. JAIN \\ Department of Pharmaceutical Sciences, MohanLal Sukhadia University, Udaipur, Rajasthan, India. Email: ashukla1007@gmail.com
}

Received: 16 October 2018, Revised and Accepted: 19 December 2018

ABSTRACT

Objective: The objective of this work was to the development of natural and modified gum based sustained-release film-coated tablets containing poorly water-soluble drug.

Methods: Tamarind seed gum (TSG), fenugreek seed gum (FSG), sodium trimetaphosphate, hydroxypropyl methylcellulose (HPMC), sodium alginate (SA), and nifedipine (NFD) were used. The core tablets of nifedipine were prepared and evaluated for weight, diameters, thickness, hardness, and disintegration time. The core tablets were coated using $2 \% \mathrm{w} / \mathrm{v}$ solution of TSG, MTSG, FSG, and MFSG. The in vitro release rate of drug from these coated tablets was compared with the release rate of drug from the tablets coated with $2 \% \mathrm{w} / \mathrm{v}$ of HPMC.

Results: The tablets coated with natural and modified TSG sustained the release of the drug up to $11 \mathrm{~h}$ and $14 \mathrm{~h}$, respectively, and natural and modified FSG sustained release the drug up to $9 \mathrm{~h}$ and $11 \mathrm{~h}$, respectively. The tablets coated with HPMC sustained released the drug up to $15 \mathrm{~h}$. The drug release profile of tablets coated with modified TSG was comparable to the release profile of tablets coated with HPMC.

Conclusion: On the basis of the release profile, it is concluded that unmodified and modified TSG can be used as release rate-controlling membrane.

Keywords: Tamarind seed gum, Fenugreek seed gum, Pharmaceutical Excipient, Natural polymer.

(c) 2019 The Authors. Published by Innovare Academic Sciences Pvt Ltd. This is an open access article under the CC BY license (http://creativecommons. org/licenses/by/4. 0/) DOI: http://dx.doi.org/10.22159/ajpcr.2019.v12i3.30296

\section{INTRODUCTION}

Film coating is a most significant unit operation in the pharmaceutical industry [1]. Film coatings are used for various purposes such as improvement of visual qualities of dosage forms, masking disagreeable taste or odor, improving stability, and modifying the release characteristics of the drug [2]. Film coating is applied to a variety of pharmaceutical products such as tablets, beads, pellets, granules, capsules, and drug crystal [3]. Polymer is the main ingredient in the majority of film-coated formulations and it may be from different origin (natural, synthetic, or semisynthetic), including cellulosic, acrylics, vinyl, and combination polymers $[4,5]$.

Fenugreek gum is a natural polymer and is extracted from the seeds of Trigonella foenum-graecum (Family Leguminosae). It is cultivated in Northern Africa, the Mediterranean, Western Asia, Northern India, and in Canada [6,7]. Application of fenugreek seed gum (FSG) has been reported as oral drug release retardant [7-9], binder [10-12], mucoadhesive [13,14], emulsifiers [15-17], suspending agent [18], gelling agent [19], and formulation of nanoparticles [20,21].

Tamarind seed gum (TSG) has wide application in the drug delivery. It has been reported that gum can be successfully extracted from tamarind seed using water solvent extraction method. The extracted gum is reported to be used as a gelling agent. It is used in the formulation of sustained-release dosage form of water-soluble and water-insoluble drugs $[21,22]$. For water-soluble drugs, the release of the drug can also control by partially cross-linking the matrix [23-25], and the extent of release can be varied by controlling the degree of cross-linking.

\section{METHODS}

Tamarind seed, fenugreek seed, sodium trimetaphosphate (STMP), nifedipine, hydroxypropyl methylcellulose (HPMC), and all other chemicals used were of analytical grade.

\section{Isolation of FSG}

The seeds of fenugreek were collected and washed with water. Then, after dried in hot air oven and seeds were crushed, soaked in water for $6 \mathrm{~h}$, boiled for $30 \mathrm{~min}$, and left for $1 \mathrm{~h}$ to allow complete release of the gum into the water. The gum was separated using a 4-fold muslin cloth bag to remove the marc from the solution. Then, ethanol (in the volumes of 3 times to the volume of filtrate) was added for precipitation of gum, the collected dried gum then grinded and passed through a \# 120 sieve and stored in a desiccator at room temperature.

\section{Isolation of TSG}

The seeds of tamarind were collected and washed with water. Then, after dried in hot air oven, the dried tamarind seeds were soaked in distilled water for 1 week, and then, the external cover was removed and obtained white part of seeds was crushed. The crushed seeds of tamarind were soaked in water for $12 \mathrm{~h}$ and boiled for $30 \mathrm{~min}$ and left for $1 \mathrm{~h}$ to allow complete release of the gum into the water. The gum was separated using a 4-fold muslin cloth bag to remove the marc from the solution. Then, ethanol (in the volumes of 3 times to the volume of filtrate) was added for precipitation of gum, the collected dried gum then grinded and passed through a \# 120 sieve and stored in a desiccator at room temperature.

\section{Modification of isolated gum with STMP}

About $1 \mathrm{~g}$ of STMP and $1 \mathrm{~g}$ of natural seed gum were taken and dissolved separately in $50 \mathrm{ml}$ of distilled water. Then, after prepared STMP and $5 \mathrm{ml}$ of $0.1 \mathrm{~N} \mathrm{NaOH}$ solutions were slowly added with stirring to $1 \mathrm{~g}$ of natural seed gum solution. The prepared solution $(100 \mathrm{ml})$ was stirred for $2 \mathrm{~h}$ and poured into Petri dish and dried at $60^{\circ} \mathrm{C}$ for $24 \mathrm{~h}$. The dried complex (modified gum) was grinded and passed through a \#120 aperture sieve and stored in an air-tight container at room temperature [26].

\section{Characterization of gum}

The physical nature of gum was characterized using Fourier transform infrared spectroscopic (FTIR) and X-ray diffraction (XRD). The scanning 
range of FTIR was $4000-500 \mathrm{~cm}^{-1}$ used. FTIR spectra are shown in Figs. 1-4.

Surface morphology of natural and modified seed gum was studied by XRD. The XRD diffraction spectra were recorded. XRD diffraction spectra of natural and modified seed gum are shown in Figs. 5-9.

\section{Drug-excipient compatibility study by FTIR}

The compatibility of the drug with excipients was studied by FTIR spectroscopy (FTIR, Bruker). All characteristic peaks of the drug were observed in the FTIR spectra of drug and excipients. Drug-excipient compatibility study by FTIR spectra is shown in Fig. 10.

\section{Evaluation of blends for core tablets $[27,28]$}

The powder mixture before compression was evaluated for the angle of repose, bulk density $\mathrm{g} / \mathrm{cm}^{3}$, tapped density $\mathrm{g} / \mathrm{cm}^{3}$, Carr's index, and Hausner ratio. Composition of core tablet and the results of evaluation are shown in Tables 1-2.

\section{Preparation of core tablets}

Core tablets of NFD were prepared using the composition given in Table 5 by direct compression method. Accurately weighed quantities of the drug, polymer mixture were passed through sieve no \#80 and mixed well for $10 \mathrm{~min}$. Sufficient quantity of the diluent microcrystalline cellulose was used to raise the total bulk of the tablets to a weight of $400 \mathrm{mg}$ each. The resulting powder blend was compressed on single tablet punching machine. The tablets were evaluated for parameters such as weight uniformity, friability, and hardness.

Table 1: Composition of core tablet

\begin{tabular}{ll}
\hline Ingredient & Quantity \\
\hline Drug & $20 \mathrm{mg}$ \\
PVP & $10 \mathrm{mg}$ \\
Lactose & $265 \mathrm{mg}$ \\
Mg. stearate & $5 \mathrm{mg}$ \\
\hline
\end{tabular}

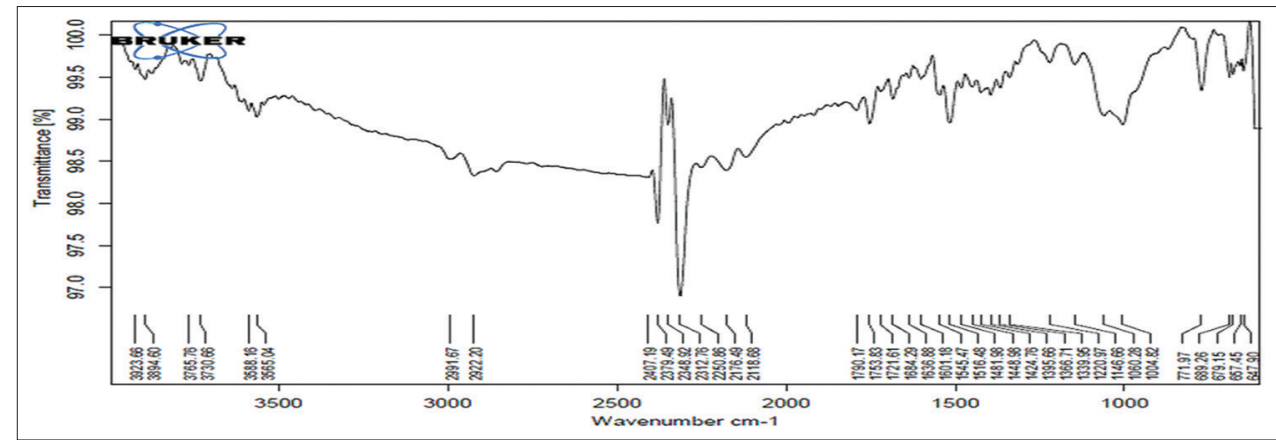

Fig. 1: Fourier transform infrared spectra of fenugreek seed gum

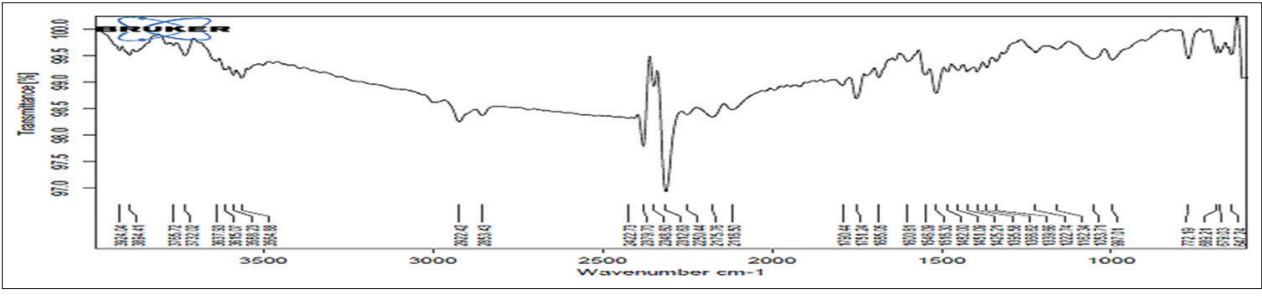

Fig. 2: Fourier transform infrared spectra of tamarind seed gum

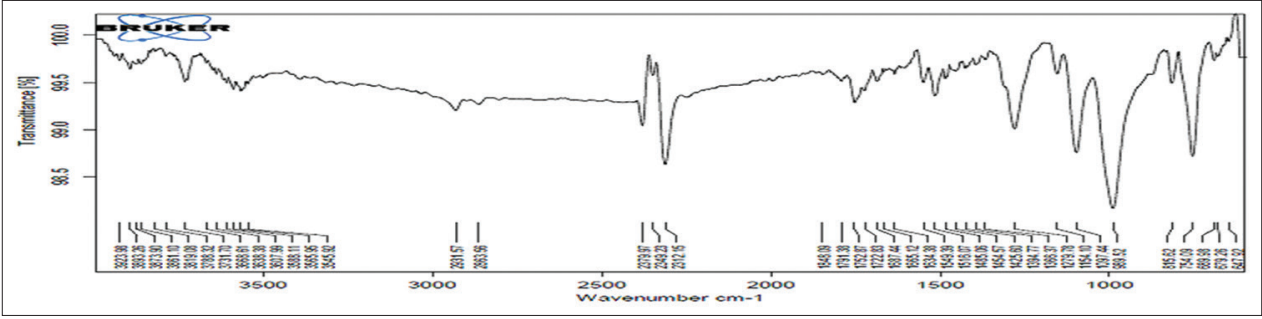

Fig. 3: Fourier transform infrared spectra of MFSG

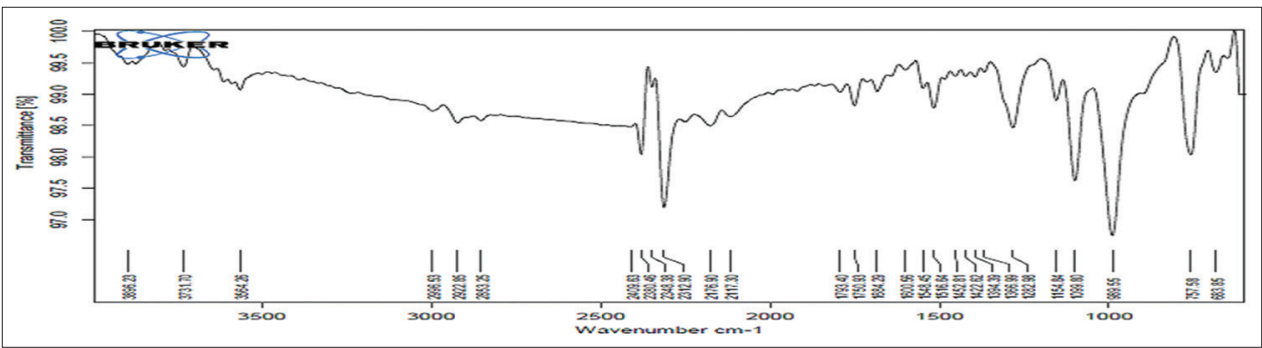

Fig. 4: Fourier transform infrared spectra of MTSG 
Evaluation of core tablets

The core tablets were evaluated for the following parameters such as weight uniformity, diameters $(\mathrm{cm})$, thickness $(\mathrm{cm})$, hardness $\mathrm{kg} / \mathrm{cm}^{2}$, and disintegration time (min.) [23]. The results of evaluated coated tablets are shown in Table 3.

\section{Dimensions}

The diameter and the thickness of tablets were determined using Vernier caliper.

\section{Weight uniformity}

A total of 20 tablets were sample out from each batch. The individually weight of tablets was taken and the average weight of tablets was calculated using the formula. The results are shown in Table 3.

Average weight of tablets $=($ total weight of tablets $) /$ number of tablets

\section{Hardness test}

The resistance of tablets to shipping or breakage under the conditions of storage, transportations, and handling before usage depends on its hardness. The hardness of tablet was measured by Pfizer hardness tester. The hardness was measured in terms of $\mathrm{kg} / \mathrm{cm}^{2}$. The results are shown in Table 3.

\section{Preparation of coating solution}

The coating solution was prepared by dissolving coating materials $2 \% \mathrm{w} / \mathrm{v}$ natural seed gum and $1 \%$ sodium alginate, $2 \% \mathrm{w} / \mathrm{v}$ modified seed gum and $1 \%$ sodium alginate, and $2 \% \mathrm{w} / \mathrm{v}$ HPMC and $1 \%$ sodium alginate, in warm water using a magnetic stirrer and $0.5 \% \mathrm{w} / \mathrm{v}$ titanium oxide (as opacifier) were added to each of above coating solution. The solutions were stirred for $60 \mathrm{~min}$ at room temperature. Composition of coating solutions is given in Table 3 .

Table 2: Evaluation of blends for core tablet

\begin{tabular}{ll}
\hline Angle of repose & \\
Bulk density g/cm & \\
Tapped density g/cm & $24.95 \pm 0.01$ \\
Carr's index\% & $0.428 \pm 0.01$ \\
Hausner ratio & $0.500 \pm 0.04$ \\
Hardness $\mathrm{kg} / \mathrm{cm}^{2}$ & $14.40 \pm 0.03$ \\
\hline
\end{tabular}

Mean \pm SD, $n=3$

Table 3: Composition of film-coating solution

\begin{tabular}{llllll}
\hline Ingredients & TSG & FSG & MTSG & MFSG & HPMC \\
\hline Batch code & $\mathrm{A}$ & $\mathrm{B}$ & $\mathrm{C}$ & $\mathrm{D}$ & $\mathrm{D}$ \\
Gum \% & 2 & 2 & 2 & 2 & 2 \\
Sodium alginate $\%$ & 1 & 1 & 1 & 1 & 1 \\
Titanium dioxide & $10 \mathrm{mg}$ & $10 \mathrm{mg}$ & $10 \mathrm{mg}$ & $10 \mathrm{mg}$ & $10 \mathrm{mg}$ \\
\hline
\end{tabular}

Viscosity of coating solution

The viscosity of prepared coating suspensions was determined with Brookfield LVDV-IV+ digital rheometer using spindle 4 at $100 \mathrm{rpm}$. The results of evaluation are shown in Table 4.

\section{Preparation of film-coated tablets}

The coating solution was prepared by dissolving the gum in warm water using a magnetic stirrer. On complete solubilization of the polymer and gum $(2 \% \mathrm{w} / \mathrm{v}$ of selected gum and $1 \% \mathrm{w} / \mathrm{v}$ of sodium alginate polymer), talc $(0.1 \% \mathrm{w} / \mathrm{v})$ as antiadherent and titanium dioxide $(0.5 \% \mathrm{w} / \mathrm{v})$ as opacifier were added. The solution was stirred for $60 \mathrm{~min}$ at room temperature. Then, prepared core tablets were dipped into prepared coating solution for $5 \mathrm{~min}$ and after coated tablets were dipped into $5 \% \mathrm{w} / \mathrm{v}$ solution of $\mathrm{CaCl}_{2}$ for $5 \mathrm{~min}$ and after were dried in hot air oven.

\section{Evaluation of film-coated tablets [27]}

The film-coated tablets were evaluated for the quality parameters, namely tablet thickness, uniformity of weight, crushing strength, and friability. A Vernier caliper was used to measure the thickness and diameters of film-coated tablets.

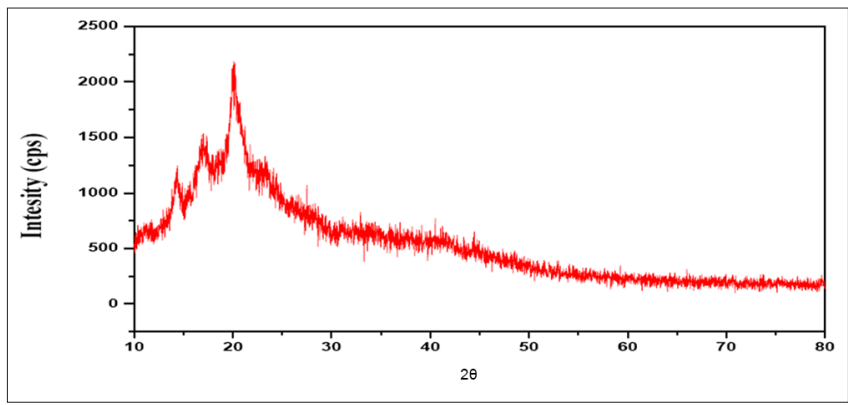

Fig. 5: X-ray diffraction spectra of fenugreek seed gum

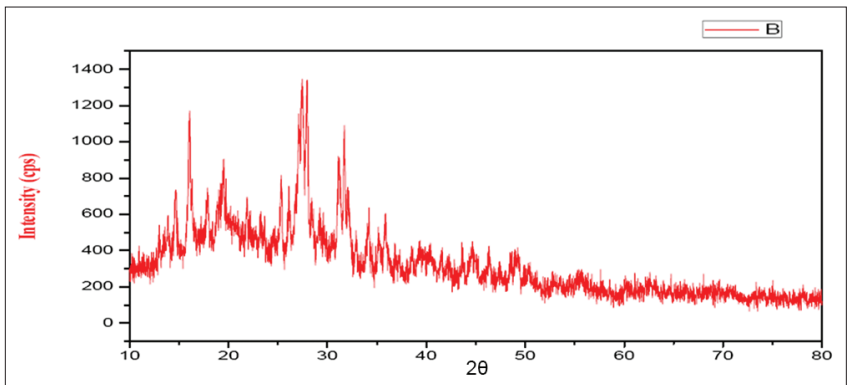

Fig. 6: X-ray diffraction spectra of MFSG

Table 4: Viscosity of coating solution

\begin{tabular}{llllll}
\hline TSG-SA & FSG-SA & MTSG-SA & MFSG-SA & HPMC & Spindle number \\
\hline $220 \pm .01 \mathrm{cp}$ & $236 \pm 0.03 \mathrm{cp}$ & $107 \pm 0.07 \mathrm{cp}$ & $103 \pm 0.02 \mathrm{cp}$ & $202 \pm 0.06 \mathrm{cp}$ & 4 \\
\hline
\end{tabular}

Mean $+\mathrm{SD}, \mathrm{n}=3$

Table 5: Evaluation of film-coated tablet

\begin{tabular}{llllll}
\hline Evaluation of coated tab. & FSG & TSG & MFSG & MTSG & HPMC \\
\hline Hardness $\mathrm{Kg} / \mathrm{m}^{2}$ & $10.0 \pm 01$ & $12.2 \pm 04$ & $9.1 \pm 02$ & $11.1 \pm 06$ & $11.7 \pm 0.03$ \\
Friability $\%$ & $0.7 \pm 02$ & $0.29 \pm 08$ & $0.49 \pm 01$ & $0.39 \pm 02$ & $0.35 \pm 01$ \\
Diameter cm & $0.9 \pm .02$ & $0.9 \pm .07$ & $0.9 \pm .04$ & $0.9 \pm .09$ & $0.9 \pm .08$ \\
Thickness cm & $0.9 \pm .08$ & $0.95 \pm .09$ & $0.9 \pm .08$ & $0.9 \pm .07$ & $0.9 \pm .06$ \\
Disintegration time (min) & $12.55 \pm 0.01$ & $17.04 \pm 0.07$ & $12.01 \pm 0.08$ & $14.10 \pm 0.04$ & $15.06 \pm 0.09$ \\
\hline
\end{tabular}

Mean \pm SD, $n=3$ 


\section{Disintegration time}

Disintegration testing of tablets was carried out in the six tablet basket rack USP disintegration apparatus. One tablet was introduced into each tube of the basket rack assembly of the disintegration apparatus without disc. The assembly was positioned in the beaker containing $900 \mathrm{ml}$ distilled water. The temperature was maintained at $37 \pm 2^{\circ} \mathrm{C}$ and operated the apparatus for $2 \mathrm{~h}$.

\section{Dissolution studies}

In vitro drug release from natural and modified TSG, natural and modified FSG, and HPMC film-coated tablets was studied, using eightstation (USP) Type II dissolution apparatus at $37 \pm 0.5^{\circ} \mathrm{C}$ and at $50 \mathrm{rpm}$ speed in $0.1 \mathrm{~N} \mathrm{HCL}$ as dissolution media for $2 \mathrm{~h}$. From the dissolution medium, $5 \mathrm{ml}$ of the samples was withdrawn at the specific time intervals and replaced with an equal volume of fresh medium $(5 \mathrm{ml})$ to maintain sink conditions. After filtration and dilution, each sample was analyzed using double-beam UV visible spectrophotometer at selected

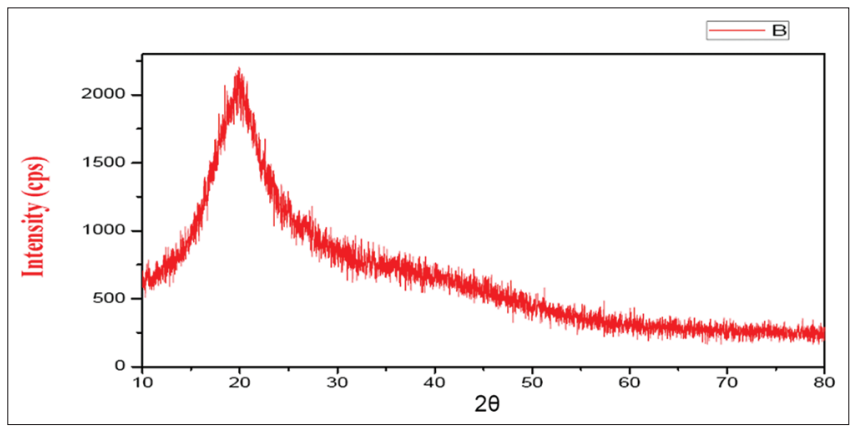

Fig. 7: X-ray diffraction spectra of tamarind seed gum

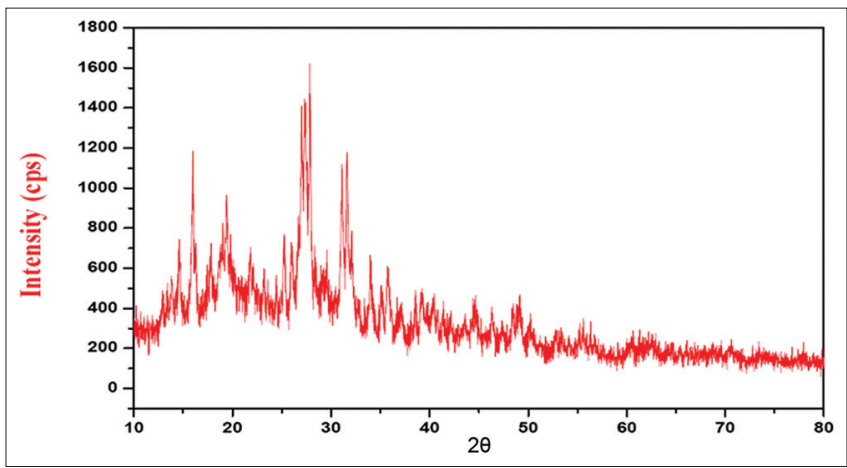

Fig. 8: X-ray diffraction spectra of MTSG
$238 \mathrm{~nm} \lambda$ max. This study was performed thrice for each batch. After $2 \mathrm{~h}$, dissolution media was replaced by phosphate buffer $\mathrm{pH} 7.4$ [23]. In vitro drug release data and graph of NFD from film-coated tablets are shown in Table 5.

\section{RESULTS AND DISCUSSION}

The FTIR spectra of the natural gum (FSG and TSG) are given in Figs. 1 and 2, respectively, which indicated that the FSG and TSG were carbohydrates in nature. Modified natural gum successfully crosslinked with STMP, characterization of modified natural gums, MFSG and MTSG were investigated by FTIR spectra of modified natural gums, MFSG and MTSG are shown in Figs. 3 and 4.

The absence of sharp peak at $1700-1800 \mathrm{~cm}^{-1}$ in the FTIR spectrum indicates that there is no carboxyl group in the extracted sample. On the other hand, the presence of peak at $1000-1200 \mathrm{~cm}^{-1}$ indicates the presence of secondary alcohols. The range of wave numbers $800-1200 \mathrm{~cm}^{-1}$ represents carbohydrates nature.

The surface characterization of natural (FSG and TSG) and modified (MFSG and MTSG), using XRD spectra of the gum was taken. The XRD spectra of natural FSG and TSG exhibited high rough surface compare to modified natural gum with pores and crevices on it, XRD spectra of natural and modified gums are shown in Figs. 5-8.

From the XRD, it was also evident that the particle size of the powders was not uniform and the size distribution was not within a narrow range. The powder contains larger to ultrafine particles. This might be the reason for the "heavy" nature of the powders. The powders exhibit a "closet" packing arrangement, in which, the smaller particles fill the voids between larger particles and reduce the bulkiness. The low porosity values also indicate this packing arrangement. The close packing can also be responsible for poor flow properties of FSG. However, after modified natural gum MTSG and MFSG is exhibited good flowing proper.

The compatibility study of the drug with excipients was studied by FTIR spectroscopy. All characteristic peaks of the drug were observed in the FTIR spectra of drug and excipients. The results showed no chemical interaction between drug and various excipients alone or in combination. The FTIR spectra of drug nifedipine (NFD) showed characteristic peaks at $3858.75 \mathrm{~cm}^{-1}$ (hydroxyl group secondary of NFD), $3670.03 \mathrm{~cm}^{-1}$ (N-H overlap of amide with $\mathrm{O}-\mathrm{H}$ of MTSG), $3555.66 \mathrm{~cm}^{-1}$ (N-H stretching, OH alcohol of MFSG), $\mathrm{O}-\mathrm{H} \mathrm{cm}^{-1}$ (glucan backbone of TSG), $3359.77 \mathrm{~cm}^{-1}$ (aromatic CH NFD), $3120.28 \mathrm{~cm}^{-1}$ (phosphonic acid), $2381.07 \mathrm{~cm}^{-1}\left(\mathrm{C} \equiv \mathrm{N}, \mathrm{C} \equiv \mathrm{C}\right.$ of NFD), $2173.78 \mathrm{~cm}^{-1}$ ( $\mathrm{C}=\mathrm{C}$ stretching of TSG), $1916.93 \mathrm{~cm}^{-1}$ ( $\mathrm{C}=0$ stretching of $\mathrm{MFSG}$ ), $1790.93 \mathrm{~cm}^{-1}$ (tertiary amide of NFD), $1681.94-1655 \mathrm{~cm}^{-1}$ (CH OH

Table 6: In vitro drug release study from film-coated tablet

\begin{tabular}{llllll}
\hline $\mathbf{h}$ & A-TSG & B-FSG & C-MFSG & D-MTSG & E-HPMC \\
\hline 0 & 0 & 0 & 0 & 0 & 0 \\
1 & $8.73 \pm 0.01$ & $15 \pm 0.02$ & $4.1 \pm 0.01$ & $4.87 \pm 0.01$ & $14.12 \pm 0.06$ \\
2 & $12.75 \pm 0.03$ & $35.47 \pm 0.01$ & $17.1 \pm 0.02$ & $10 \pm 0.03$ & $20.83 \pm 0.08$ \\
3 & $17.4 \pm 0.01$ & $50.7 \pm 0.04$ & $20.3 \pm 0.01$ & $15.45 \pm 0.01$ & $36.6 \pm 0.01$ \\
4 & $41.2 \pm 0.04$ & $72.1 \pm 0.03$ & $33.12 \pm 0.07$ & $25.8 \pm 0.02$ & $43.47 \pm 0.02$ \\
5 & $57.3 \pm 0.02$ & $81.65 \pm 0.01$ & $37.05 \pm 0.08$ & $41.6 \pm 0.03$ & $47.51 \pm 0.03$ \\
6 & $74.3 \pm 0.01$ & $87.25 \pm 0.05$ & $55.84 \pm 0.01$ & $51.1 \pm 0.08$ & $59.32 \pm 0.01$ \\
7 & $80.6 \pm 0.05$ & $92.1 \pm 0.03$ & $60.9 \pm 0.02$ & $70.06 \pm 0.01$ & $66.71 \pm 0.08$ \\
8 & $89.6 \pm 0.01$ & $97.65 \pm 0.01$ & $69.4 \pm 0.01$ & $82.7 \pm 0.02$ & $74.48 \pm 0.07$ \\
9 & $91.3 \pm 0.02$ & $98.61 \pm 0.002$ & $71.7 \pm 0.06$ & $84.05 \pm 0.03$ & $78.54 \pm 0.01$ \\
10 & $93.6 \pm 0.01$ & & $76 \pm 0.03$ & $86.71 \pm 0.02$ & $83.95 \pm 0.03$ \\
11 & $98.6 \pm 0.03$ & & $81.9 \pm 0.02$ & $88.32 \pm 0.04$ & $90.41 \pm 0.02$ \\
12 & & $91.9 \pm 0.02$ & $92.08 \pm 0.01$ & $94.93 \pm 0.01$ \\
14 & & & $95.73 \pm 0.02$ & $97.3 \pm 0.04$ \\
15 & & & & $98.73 \pm 0.07$ \\
\hline
\end{tabular}




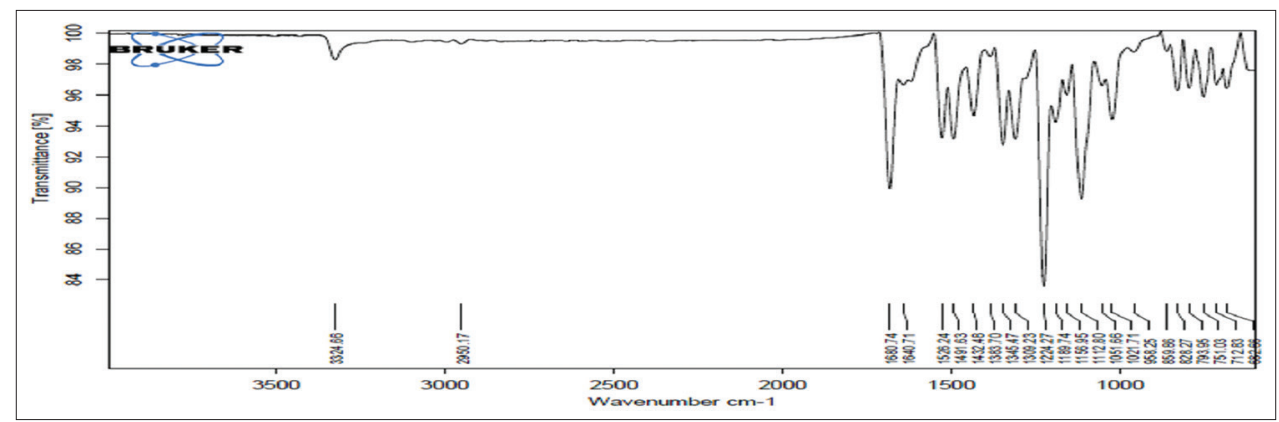

Fig. 9: Fourier transform infrared spectra of nifedipine pure

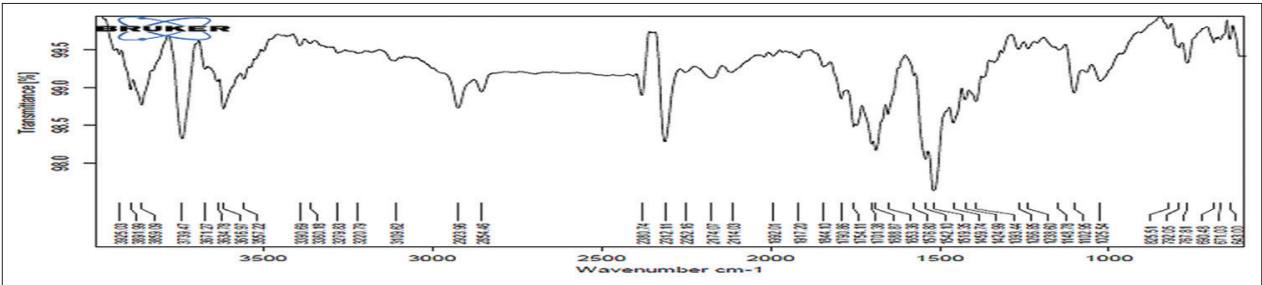

Fig. 10: Fourier transform infrared spectra for drug-excipient compatibility study of nifedipine

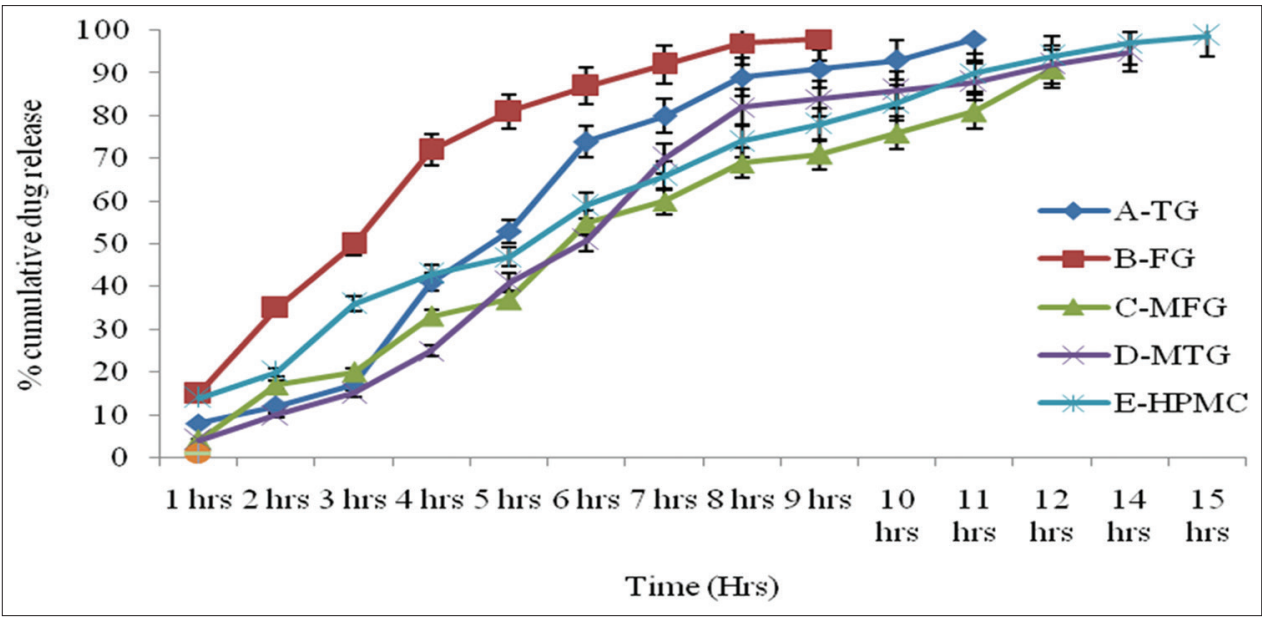

Fig. 11: In vitro drug release study from film-coated tablet of nifedipine . (mean $\pm S D, n=3$ )

stretching vibration of FSG), $1576.73 \mathrm{~cm}^{-1}$ (CH2 stretching of TSG), $1521.64 \mathrm{~cm}^{-1}$ (N-O nitro compound NFD), $1423.99 \mathrm{~cm}^{-1}$ (OH bending carboxylic acid MTSG), $1277.67 \mathrm{~cm}^{-1}$ (C-O alkyl aryl ether of NFD), $1097.50 \mathrm{~cm}^{-1}$ primary alcohol of NFD), and $1053 \mathrm{~cm}^{-1}$ (CH stretching vibration of FSG). It is clear that functionalities of drug have remained unchanged including intensities of the peak. Hence, in physical mixture, no interaction was found, which supports the formulation of the formulation of film-coating tablets. Compatibility study of nifedipine and excipients FTIR spectra are shown in Figs. 9 and 10.

Blends of nifedipine core tablets were prepared. All the ingredients mixed well and evaluated as parameters such as angle of repose, bulk density, tapped density, Car's index, and Hausner ratio, composition of core tablets is shown in Table 1 . The results of these parameters were found in the range of angle of repose $24.95 \pm 0.01$, bulk density $0.428 \pm 0.11$, tapped density $0.500 \pm 0.04$, Car's index $14.40 \pm 0.03$, Hausner ratio $1.4 \pm 0.07$, and hardness $\mathrm{kg} / \mathrm{cm}^{2} 6 \pm 0.01$. The results of evaluated parameters represented that the property of blends was excellent. Evaluation results of nifedipine core tablets are shown in Table 2.

Composition of coating blends is shown in Table 3. The viscosity of coating solution was determined using Brookfield viscometer spindle- 4 at $100 \mathrm{rpm}$. Results are shown in Table 4.
The evaluation results of film-coated nifedipine tablets are shown in Table 5. The coated nifedipine tablets with HPMC had better hardness compared to those coated with fenugreek and TSG, and the disintegration time of core tablets increased from $3 \mathrm{~min}$ (core) to $12.33,10.61,8.93$, and 9.40 min after coating with FSG. The order of disintegration time of formulation was found: $\mathrm{HPMC}>\mathrm{TSG}>\mathrm{FSG}>$ core. Developed film-coating tablets using FSG, TSG, MFSG, MTSG, HPMC, diameter $(\mathrm{cm}) 0.9 \pm 0.02,0.9 \pm 0.07,0.9 \pm 0.04,0.9 \pm 0.09$, and $0.9 \pm 0.08$, and thickness $(\mathrm{cm}) 0.9 \pm 0.08,0.95 \pm 0.09,0.9 \pm 0.08,0.9 \pm 0.07$, and $0.9 \pm 0.06$ were found.

The drug dissolution profile of the coated tablets is shown in Table 6. Coated tablets, coated with natural seed gum combination of $2 \% \mathrm{w} / \mathrm{v}$ FSG-1 $\% \mathrm{w} / \mathrm{v}-\mathrm{SA}$ and $2 \% \mathrm{w} / \mathrm{v}$ TSG-1\% w/v-SA, modified seed gum $2 \% \mathrm{w} / \mathrm{v}$ MFSG- $1 \% \mathrm{w} / \mathrm{v}-\mathrm{SA}, 2 \% \mathrm{w} / \mathrm{v}$ MTSG- $1 \% \mathrm{w} / \mathrm{v}-\mathrm{SA}$, and $2 \% \mathrm{w} / \mathrm{v}$ HPMC- $1 \% \mathrm{w} / \mathrm{v}-\mathrm{SA}$, respectively, shown. The drug release rate of coated tablets was found up to (FSG) $8 \mathrm{~h}$, (TSG) $11 \mathrm{~h}$, (MFSG) $12 \mathrm{~h}$, (MTSG) $14 \mathrm{~h}$, and (HPMC-SA) $15 \mathrm{~h}$, respectively. Hence, drug release rate of TSG film-coated tablets was sustained as compare to core tablets. Hence, TSG can be used for the formulation of sustained release of drugs. The drug dissolution profile of the coated tablets is shown in Fig. 11. 


\section{CONCLUSION}

The potential of natural and modified FSG and TSG was investigated using nifedipine as model drug and found that natural and modified form of TSG better film-coating potential than fenugreek gum and similar to near standard film-forming agent HPMC. The coated tablets were evaluated using parameters as uniformity of weight, friability, disintegration time, and dissolution profiles. TSG can be used for the improvement of visual qualities of dosage forms, masking disagreeable taste or odor, improving stability, and modifying the sustained-release characteristics of the drug.

\section{ACKNOWLEDGMENTS}

The authors would like to thank the Department of Pharmaceutical Sciences, Department of Physics, and Department of Chemistry, Faculty of Sciences, Mohanlal Sukhadia University, Udaipur, Rajasthan, India, for providing all necessary facilities.

\section{AUTHORS' CONTRIBUTIONS}

All the authors have contributed equally.

\section{CONFLICTS OF INTEREST}

No conflicts of interest related with this work.

\section{REFERENCES}

1. Sauer D, Watts AB, Coots LB, Zheng WC, McGinity JW. Influence of polymeric subcoats on the drug release properties of tablets powder-coated with pre-plasticized eudragit L 100-55. Int J Pharm 2009;367:20-8.

2. Rhodes CT, Porter SC. Coatings for controlled-release drug delivery systems. Drug Dev Ind Pharm 1998;24:1139-54.

3. Kwok TS, Sunderland BV, Heng PW. An investigation on the influence of a vinyl pyrrolidone/vinyl acetate copolymer on the moisture permeation, mechanical and adhesive properties of aqueous-based hydroxypropyl methylcellulose film coatings. Chem Pharm Bull (Tokyo) 2004;52:790-6.

4. Rowe RC. The effect of some formulation and process variables on the surface roughness of film-coated tablets. J Pharm Pharmacol 1978;30:669-72.

5. Singh K, Kumar A, Langyan N, Ahuja M. Evaluation of Mimosa pudica seed mucilage as sustained-release excipient. AAPS PharmSciTech 2009;10:1121-7.

6. Shukla A, Bukhariya V, Mehta J, Bajaj J, Charde R, Charde M, et al. Herbal remedies for diabetes: An overview. Int J Biomed Adv Res 2011;2:57-68

7. Shukla AK, Kumar M, Bishnoi RS, Jain CP. Review article application of fenugreek seed gum: In novel drug delivery. Asian J Biomat Res 2017;3:1-10

8. Brummer Y, Cui W, Wang Q. Extraction, purification and physicochemical characterization of fenugreek gum. Food Hydrocoll 2003;17:229-36

9. Nokhodchi A, Nazemiyeh H, Khodaparast A, Sorkh-Shahan T, Valizadeh $\mathrm{H}$, Ford JL, et al. An in vitro evaluation of fenugreek mucilage as a potential excipient for oral controlled-release matrix tablet. Drug Dev Ind Pharm 2008;34:323-9.

10. Ali N, Hossein N, Afagh K, Tarifeh S, Hadi V, Ford JL. An in-vitro evaluation of fenugreek mucilage as a potential excipient for oral controlled-release matrix tablet. Drug Dev and Ind Pharm 2008; 34:323-29.

11. Sav AK, Fule RA, Meer TA, Amin P. Synthesis and evaluation of octenyl succinate derivative of fenugreek gum as extended release polymer. J Pharm Investig 2013;43:417-29.

12. Nitalikar MM, Patil RA, Dhole SW, Sakarkar DM. Evaluation of fenugreek seed husk as tablet binder. Int J Pharm Res Dev 2010;2:21-3.

13. Nitalikar MM, Patil RA, Dhole SD, Sakarkar DM. Formulation of fenugreek husk as tablet binder. Int J Pharm Res Dev 2013;43:417-29.

14. Tavakoli N, Varshosaz J, Ghannadi A. Bavarsad N. Evaluation of Trigonella foenum-graecum seeds gum as a novel tablet binder. Int $\mathrm{J}$ Pharm Pharm Sci 2012;4:97-101.

15. Nayak AK, Pal D, Das S. Calcium pectinate-fenugreek seed mucilage mucoadhesive beads for controlled delivery of metformin $\mathrm{HCl}$. Carbohydr Polym 2013;96:349-57.

16. Dutta R, Bandyopadhyay AK. Development of a new nasal drug delivery system of diazepam with natural mucoadhesive agent from Trigonella foenum-graecum L. J Sci Ind Res 2005;64:973-7.

17. Senthil V, Sripreethi D. Formulation and evaluation of paracetamol suspension from Trigonella foenum graecum mucilage. J Adv Pharm Edu Res 2011;1:225-33

18. Kaltsa O, Spiliopoulou N, Yanniotis S, Mandala I. Stability and physical properties of model macro-and nano/submicron emulsions containing fenugreek gum. Food Hydrocoll 2016;61:625-32.

19. Sav AR, Meer TS, Fule RA, Amin PD. Investigational studies on highly purified fenugreek gum as emulsifying agent. J Disp Sci Technol 2013;34:657-62.

20. Gowthamrajan K, Kulkarni GT, Muthukumar A. Evaluation of fenugreek mucilage as gelling agent. Int J Pharm Exp 2002;3:16-9.

21. Seetharaman S, Balya H, Kuppusamy G. Preparation and evaluation of cefixime nanoparticles prepared using fenugreek seed mucilage and chitosan as natural polymers. Int J Pharm Clin Res 2016;8:179-88.

22. Bera H, Gaini C, Kumar S, Sarkar S, Boddupalli S, Ippagunta SR, et al. HPMC-based gastroretentive dual working matrices coated with ca $(+2)$ ion crosslinked alginate-fenugreek gum gel membrane. Mater Sci Eng C Mater Biol Appl 2016;67:170-81.

23. Shukla AK, Bishnoi RS, Dev SK, Kumar M, Fenin V. Biopharmaceutical classification system: Tool based prediction for drug dosage formulation. Adv Pharm J 2017;2:204-9.

24. Shukla AK, Bishnoi RS, Dev SK, Kumar M, Fenin V, Jain CP. Applications of tamarind seeds polysaccharide-based copolymers in controlled drug delivery: An overview. Asian J Pharm Pharm 2018;4:23-30

25. Garg A, Garg S, Kumar M, Kumar S, Shukla AK, Kaushik SP. Applications of natural polymers in mucoadhesive drug delivery: An overview. Adv Pharm J 2018;3:38-42.

26. Reddy MM, Reddy JD, Moin A, Shivakumar HG. Formulation of sustained-release matrix tablets using cross-linked karaya gum. Trop J Pharm Res 2012;11:185-92.

27. Jani GK, Shah DP. Evaluation of mucilage of Hibiscus rosasinensis Linn as rate controlling matrix for sustained release of diclofenac. Drug Dev Ind Pharm 2008;34:807-16.

28. Shukla AK, Bishnoi RS, Kumar M, Jain CP. Isolation and characterization of natural and modified seed gumAsian Journal of Pharmac and Pharmaco 2019; 5(2): 409-418. 